\title{
Pulmonary Mycoses Diagnosed Using Exfoliative Cytology: Infection or Colonization?
}

\author{
Lavleen Singh $^{\mathrm{a}}$ Deepali Jain ${ }^{\mathrm{a}}$ Karan Madan $^{\mathrm{b}}$ Sandeep R. Mathur ${ }^{\mathrm{a}}$ \\ Priti Chatterjee $^{a}$ Randeep Guleria ${ }^{b}$ Venkateswaran K. Iyer ${ }^{a}$
}

Departments of a Pathology and ${ }^{b}$ Pulmonary Medicine and Sleep Disorders, All India Institute of Medical Sciences, New Delhi, India

\section{Key Words}

Pulmonary mycoses · Exfoliative cytology · Colonization · Infection

\begin{abstract}
Objectives: Flexible bronchoscopy with exfoliative cytology is an important tool for the diagnosis of pulmonary fungal infections. The question of colonization versus true fungal infection is of critical importance. Study Design: A 5-year retrospective analysis of all cases of pulmonary fungal infection diagnosed using exfoliative cytology was performed. Clinical, radiological, bronchoscopy and histopathology findings were recorded. Results: A total of 69 cases of mycoses were retrieved. The most common fungal organism identified was Aspergillus followed by Candida and Pneumocystis. Most cases of Aspergillus and Candida in cytological specimens presented as a pulmonary mass or endobronchial growth and were diagnosed as carcinomas in biopsy specimens, thus representing colonization. All cases of Pneumocystis with bilateral ground glass infiltrates and cryptococcosis with parenchymal mass lesion in radiology represented true infection. Histoplasma was identified in pleural fluid from a known case of lung carcinoma. Conclusion: Aspergillus and
\end{abstract}

Candida species are the most common fungal organisms. Most of these represent colonization of malignant growths. However, true fungal infections may also present as mass lesions and may masquerade malignancy clinically. Fluid cytological examination is an important diagnostic modality for pulmonary mycoses; however, it is important to correlate results with clinical, bronchoscopy and biopsy findings for accurate diagnosis and appropriate management.

(C) 2013 S. Karger AG, Basel

\section{Introduction}

Fungal infections continue to be an important cause of morbidity and mortality, especially in immunocompromised and cancer patients $[1,2]$. A timely and accurate diagnosis is important but often challenging due to atypical clinical presentation $[3,4]$. A reliable diagnosis can be made by demonstration of fungal invasion in tissue biopsy or by culture studies [5]. The main disadvantage of tissue examination is the invasive nature of the test and the disadvantage of culture studies is the long waiting period for results to be available and the relative insensitivity [6]. Moreover, some of the fungi-like Pneumocystis

\section{KARGER}

E-Mail karger@karger.com www.karger.com/acy
(C) 2013 S. Karger AG, Basel

0001-5547/13/0576-0604\$38.00/0
Correspondence to: Dr. Deepali Jain Department of Pathology All India Institute of Medical Sciences Ansari Nagar, New Delhi 110029 (India) E-Mail deepalijain76@gmail.com 
Table 1. Fungal organisms diagnosed using exfoliative cytology

\begin{tabular}{lcllll}
\hline & $\begin{array}{l}\text { Asper- } \\
\text { gillus }\end{array}$ & Candida & $\begin{array}{l}\text { Pneumo- } \\
\text { cystis }\end{array}$ & $\begin{array}{l}\text { Crypto- } \\
\text { coccus }\end{array}$ & $\begin{array}{l}\text { Histo- } \\
\text { plasma }\end{array}$ \\
\hline BW & 7 & 3 & & & \\
BAL & 27 & 6 & 10 & 4 & 1 \\
PE & 1 & 1 & & & \\
Sputum & 5 & 4 & & & \\
\hline
\end{tabular}

$\mathrm{BW}=$ Bronchial washing; $\mathrm{BAL}=$ bronchoalveolar lavage $\mathrm{PE}=$ pleural effusion.

cannot be cultured in a laboratory, and thus, cytological examination remains the mainstay of diagnosis $[7,8]$. Serologic tests are often unhelpful because of the poor antibody responses of immunosuppressed patients. Fungal antigen detection and molecular techniques are emerging as important tools in the rapid diagnosis of several fungal infections. However, the former is limited by low sensitivity and specificity and the latter by high cost and erroneous false-negative results in patients on antifungal therapy [9-11]. The roentgenographic appearance of pulmonary mycotic infections is highly variable and may frequently mimic mass lesion and pneumonia caused by other organisms $[3,12,13]$. Exfoliative cytology and expectorated sputum may be helpful in the diagnosis of mycotic infections, thus avoiding an invasive procedure, a longer waiting period and thereby ensuring improved patient survival. However, in exfoliative cytology specimens, the question of colonization versus true fungal infection is of critical importance and has important treatment implications. The issue can be resolved by correlating clinical and imaging findings. Almost all pulmonary neoplasms can be colonized by superimposed fungal organisms $[14,15]$. This study was undertaken to analyze the clinical spectrum of patients in whom a fungal organism was isolated in exfoliative cytological specimens. The clinical profile of patients, imaging and bronchoscopy findings were retrieved and compared with concurrent tissue diagnosis if available. The utility of exfoliative cytology in the diagnosis of pulmonary mycoses is also discussed.

\section{Material and Method}

All cases of pulmonary mycoses diagnosed in exfoliative cytology specimens, pleural fluid and expectorated sputum were retrieved from the cytopathology archives, Department of Pathology, All India Institute of Medical Sciences, New Delhi, India, over a period of 5 years (2008-2012). The samples included bronchial washings $(\mathrm{n}=10)$, bronchoalveolar lavage (BAL; $\mathrm{n}=47)$, pleural fluid $(n=3)$ and sputum $(n=9)$. A total of 69 cases of pulmonary mycoses were retrieved. The clinical symptoms, immune status of the patient, relevant radiological investigations and flexible bronchoscopy findings were recorded. A correlation with tissue diagnosis was made wherever available.

Identification of fungal organisms was done using Papanicolaou, Giemsa and methenamine silver stains, according to previously described features [16-23]. The slides were reviewed to confirm the original diagnosis, and an attempt was made to classify these fungal infections as colonization or primary pathological lesion based on clinical, imaging, bronchoscopy and tissue diagnosis features.

\section{Results}

\section{Clinical Features}

There were 53 men and 16 women with a male:female ratio of 3.3:1. The age of the patients ranged from 9 months to 77 years, with a mean age of $47.80 \pm 20.03$ years.

The most common clinical complaints were cough, hemoptysis, expectoration and shortness of breath.

Six of the 69 patients presented with nonresolving pneumonia and acute respiratory distress syndrome. Two patients affected by Wegener's granulomatosis had cytoplasmic anti-neutrophil cytoplasmic antibody (c-ANCA) positivity on serology and necrotizing nodules in bilateral lungs. There were 3 patients with acute lymphoblastic leukemia and 10 were postrenal transplant patients.

Twenty-seven patients were found to be immunocompromised due to various underlying conditions including chemotherapy for acute lymphoblastic leukemia $(n=3)$, chemotherapy for solid malignancy $(\mathrm{n}=1)$, steroid therapy $(\mathrm{n}=4)$, postrenal transplant $(\mathrm{n}=10)$, longstanding diabetes $(n=3)$, and disseminated tuberculosis $(n=6)$.

\section{Cytologic Examination}

There were 2 Papanicolaou- and 1 Giemsa-stained smears in each case. One methenamine silver-stained smear was available for demonstration of fungal profiles. The most common fungal organism identified was Aspergillus ( 40 cases; $58.82 \%$ ), followed by Candida ( 14 cases; $20.6 \%$ ) and Pneumocystis (10 cases; $14.7 \%)$. Four cases of Cryptococcus $(3 ; 4.4 \%)$ and $1(1.5 \%)$ case of Histoplasma were also recognized (table 1 ).

Aspergillus showed septate hyphae branching at an angle of approximately $45^{\circ}[18,21]$. 
Fig. 1. a, b Gomory silver methenamine stain of BAL fluid shows thin, slender pseudohyphae and spores of Candida in a diabetic patient. c Foamy alveolar cast in BAL fluid in a case of Pneumocystis. Papanicolaou stain. $\times 200$. d Cryptococcus was identified as small round refractile bodies present intracellularly in a multinucleated giant cell in BAL fluid. Papanicolaou stain. $\times 400$.
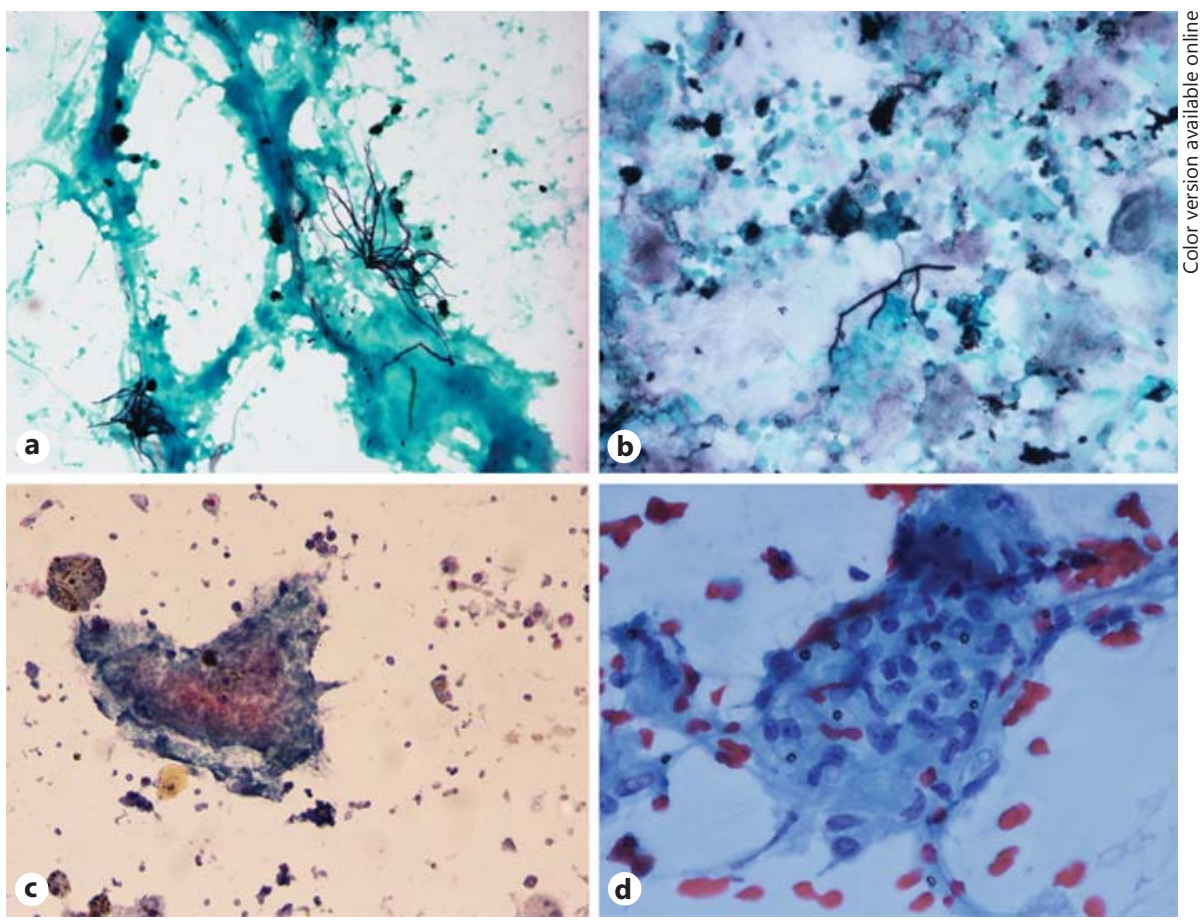

Table 2. Bronchoscopic, radiological and immune work-up in patients with colonization

\begin{tabular}{|c|c|c|c|c|c|c|c|}
\hline \multirow[t]{2}{*}{ Fungus } & \multicolumn{3}{|c|}{ Flexible bronchoscopy } & \multicolumn{2}{|l|}{ Radiology } & \multicolumn{2}{|c|}{ Immune status } \\
\hline & normal & $\begin{array}{l}\text { airway narrowing } \\
\text { with normal } \\
\text { mucosa }\end{array}$ & $\begin{array}{l}\text { endobron- } \\
\text { chial growth }\end{array}$ & lung mass & consolidation & $\begin{array}{l}\text { compro- } \\
\text { mised }\end{array}$ & competent \\
\hline Aspergillus & 1 & 1 & 23 & 23 & 2 & & 25 \\
\hline Candida & 1 & 1 & 8 & 8 & 2 & & 10 \\
\hline
\end{tabular}

Table 3. Bronchoscopic, radiological and immune work-up in patients with invasive mycoses

\begin{tabular}{|c|c|c|c|c|c|c|c|}
\hline \multirow[t]{2}{*}{ Fungus } & \multicolumn{3}{|c|}{ Flexible bronchoscopy } & \multicolumn{2}{|l|}{ Radiology } & \multicolumn{2}{|c|}{ Immune status } \\
\hline & normal & $\begin{array}{l}\text { airway narrowing } \\
\text { with normal mucosa }\end{array}$ & growth & lung mass & $\begin{array}{l}\text { consolidation/ } \\
\text { cavity/ground } \\
\text { glass opacity }\end{array}$ & $\begin{array}{l}\text { compro- } \\
\text { mised }\end{array}$ & competent \\
\hline Aspergillus & 12 & 2 & 1 & 2 & 13 & 14 & 1 \\
\hline Candida & 3 & & 1 & 1 & 3 & 4 & \\
\hline Pneumocystis & 10 & & & & 10 & 8 & 2 \\
\hline Cryptococcus & 3 & & & 3 & 1 & & 4 \\
\hline Histoplasma & 1 & & & & 1 & 1 & \\
\hline
\end{tabular}



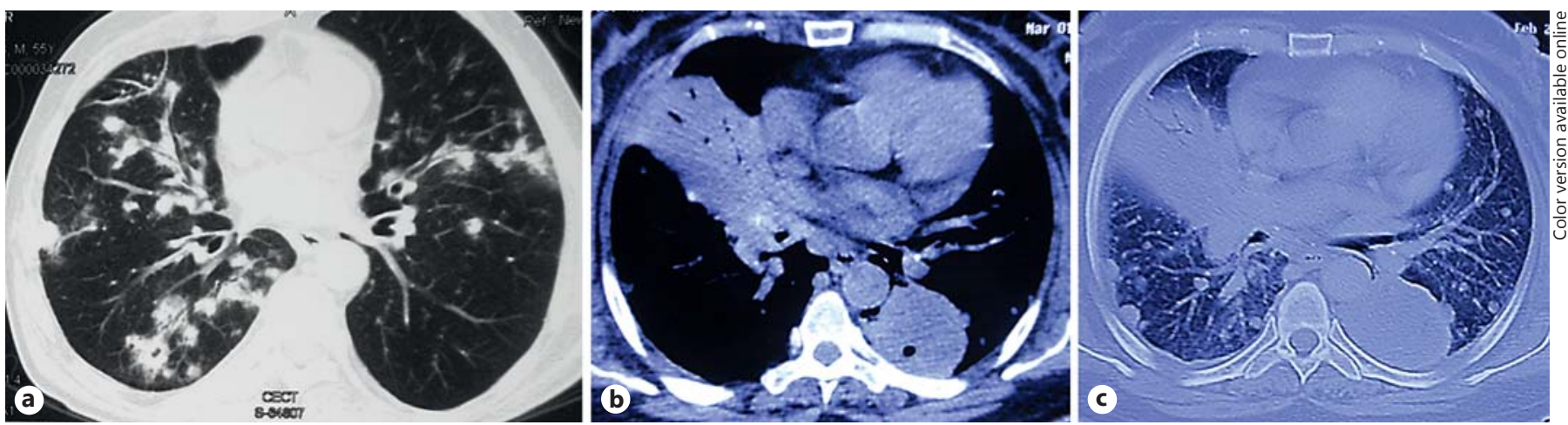

Fig. 2. a Thorax CT (lung window section) demonstrating multiple nodular opacities in an airway-centered pattern in bilateral lungs. Many of the opacities show a surrounding halo. b Contrast-enhanced thorax CT (mediastinal window) shows a well-defined left lower lobe mass and a large area of mass-like consolidation in the right middle lobe. $\mathbf{c}$ The corresponding lung window section reveals multiple variable-sized and randomly distributed nodules in the bilateral lungs.

Fig. 3. a Photomicrograph of a lung biopsy shows multiple cryptococci within alveolar spaces and the interstitium. H\&E. $\times 200$. b Cryptococci stained blue by Alcian blue periodic acid Schiff. c, d Periodic acid Schiff (c) and Gomory silver methenamine (d) stains show invasive aspergillosis in lung biopsy as thin branching and septate hyphal organisms with surrounding ischemic necrosis.
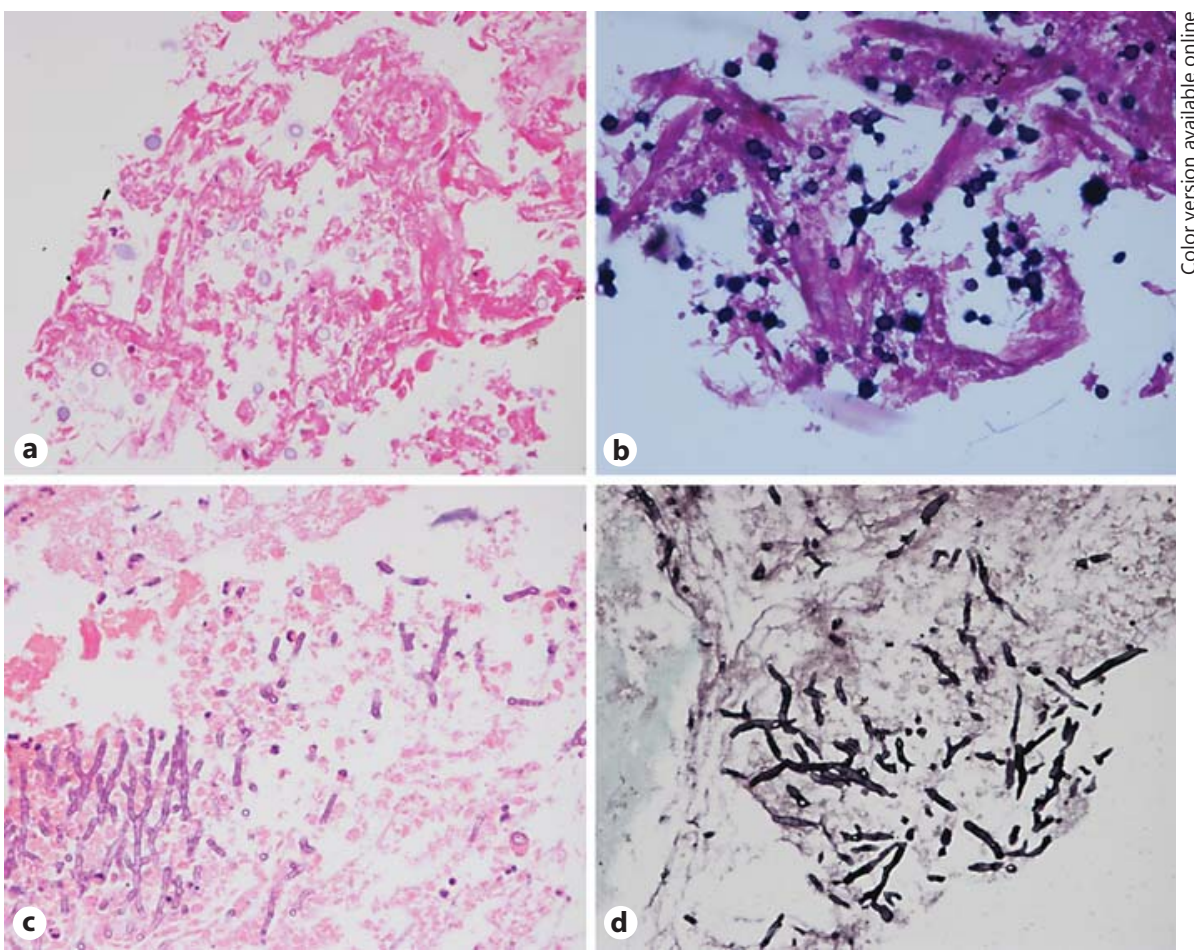

Candida was seen as yeast $(2-5 \mu \mathrm{m})$ and pseudohyphae (fig. 1a, b) [22]. Pneumocystis was identified in the BAL fluid by characteristic cysts and clusters, foamy alveolar macrophages and foamy alveolar casts (fig. 1c) [16, 17]. Cryptococcus was recognized as encapsulated yeast, $4-10 \mu \mathrm{m}$ in diameter, with a clear halo (fig. 1d) $[19,20]$. Histoplasma yeast was ovoid and small, with a diameter of 2-5 $\mu \mathrm{m}$ and narrow-based budding [23].

Pulmonary Mycoses

\section{Radiology and Histology}

Most cases of Aspergillus ( $n=25)$ and Candida $(n=9)$ demonstrated a pulmonary parenchymal mass or endobronchial growth while correlating with imaging and flexible bronchoscopy findings. Twenty-two cases of Aspergillus $(22 / 25 ; 88 \%)$ and 8 cases $(8 / 9 ; 89 \%)$ of Candida recognized on exfoliative cytology examinations were eventually diagnosed as non-small cell carcinoma in bi-

Acta Cytologica 2013;57:604-610 
opsy tests. One case of endobronchial leiomyoma was also observed with Aspergillus colonization. Of these 31 fungal colonization cases, 3 cases were positive for malignant cells in cytology specimens.

No endobronchial growth was identified in 4 cases where Aspergillus and Candida were found as colonizers. A biopsy of consolidated lung parenchyma showed evidence of non-small cell carcinoma in these 4 cases (table 2).

A total of 35 cases represented fungal colonization. There were 6 cases of invasive primary pulmonary fungal infection, which showed endobronchial growth or mass lesion on imaging (table 3 ).

Most of the pathogenic mycoses presented with consolidation/cavitary lesion on imaging (fig. 2a) and had normal bronchoscopic examination. Cases of pneumocystis infection exhibited bilateral ground glass infiltrates on imaging. However, 3 cases of cryptococcal infection showed parenchymal mass lesion in radiology examinations (fig. 2b, c). Three of the 4 cases showed concurrent invasive cryptococcosis in biopsy specimens (fig. 3a, b), and in 1 case, there was positive cerebrospinal fluid cytology for cryptococcus. Invasive aspergillosis was diagnosed in 1 case of Aspergillus where bronchoscopy showed growth (fig. 3c, d). No further clinical and histo-

Table 4. Pulmonary mycoses using cytology

\begin{tabular}{lccc}
\hline Fungus & Colonization & Fungal infection & Total \\
\hline Aspergillus & 25 & 15 & 40 \\
Candida & 10 & 4 & 14 \\
Pneumocystis & - & 10 & 10 \\
Cryptococcus & - & 4 & 4 \\
Histoplasma & - & 1 & 1 \\
\hline Total & 35 & 34 & 69 \\
\hline
\end{tabular}

logic information could be obtained in 1 case of candida with endobronchial growth.

A total of 34 cases represented true fungal infection (table 4).

\section{Immune Status}

Twenty-seven of 34 patients with mycotic infection had various immunocompromised states, as shown in table 5 .

\section{Discussion}

The diagnosis of pulmonary fungal infections and the differentiation of true mycoses from colonization is a challenge for clinicians and pathologists because of atypical clinical and radiological presentation, coexistence with other infectious and noninfectious/neoplastic conditions, the relative inability to cultivate and the long time period required for the culture of organisms $[6,24]$.

The imaging findings of pulmonary mycoses are relatively nonspecific. Invasive mycoses masquerading as malignant growth is not uncommon; also, there are case reports of tumors suspected of fungal infection on imaging $[6,25]$.

Tissue diagnosis is relatively specific, although it suffers from a morphologic overlap, and an invasive procedure may not be a feasible option in debilitated patients $[6,26]$.

The exfoliative cytology specimen may aid in the early diagnosis of pulmonary fungal infection; however, the differentiation of colonization of malignant growth versus true pulmonary mycoses remains a critical issue.

The possibility of colonization on malignant growth in a given fungal infection should always be considered in patients with lung mass in radiology examinations or

Table 5. Mycoses and underlying condition

\begin{tabular}{|c|c|c|c|c|c|}
\hline & Aspergillus & Candida & Pneumocystis & Histoplasma & Cryptococcus \\
\hline Chemotherapy for ALL & 3 & & & & \\
\hline Chemotherapy for solid tumor & & & & 1 & \\
\hline Postrenal transplant & 2 & & 8 & & \\
\hline Steroid therapy & 3 & 1 & & & \\
\hline Diabetes mellitus & & 3 & & & \\
\hline Disseminated tuberculosis & 6 & & & & \\
\hline
\end{tabular}


a visible endobronchial growth in flexible bronchoscopic examinations. In the present study, nearly half $(31 / 69)$ of the specimens diagnosed as mycoses using cytology were found to have growth or mass lesions in radiology and carcinoma in biopsy examinations. When atypical or malignant cells accompany fungal organisms, it becomes easy to diagnose colonization, as shown in 3 of our cases. However, reactive atypical cells associated with fungal infection should be differentiated from malignant cells [27].

On the other hand, invasive fungal infections are one of the important life-threatening conditions associated with immunocompromised states and require immediate antifungal treatment; thus, an early and accurate diagnosis becomes imperative.

Pulmonary mycoses can manifest radiologically as lung consolidation, nodules or hilar/mediastinal adenopathy alone. Effusions may occasionally occur in some fungal lung infections $[28,29]$. Clinically and radiologically, they may also present as a neoplastic lesion similar to 6 of our patients subsequently diagnosed as Cryptococcus $(n=4 / 6)$, Aspergillus $(n=1 / 6)$ and Candida $(n=1 / 6)$. It is prudent to look out for immunocompromised states if a patient is diagnosed with pulmonary mycoses on cytological examination as most of these fungi are true pathogens. A clue for a given fungus being pathogenic and not colonized is the underlying immune status of the patient. However, a substantial proportion of fungal infections have been reported in apparently immunocompetent patients [30, 31].

Four cases of Cryptococcus and 2 cases of Pneumocystis infection in the present series were apparently immunocompetent. Experiments show that Pneumocystis organisms can replicate in the lung alveolus of immunocompetent hosts and remain infectious [32]. Cryptococcosis continues to cause significant morbidity and mortality in immunocompetent patients $[33,34]$. Although there are reports of cryptococcal colonization in neoplastic growths, we have found no such cases [35, 36].

There is no morphological difference in cytological examinations if a particular fungus is colonized or if there is a true infection, unlike in biopsy specimens, where ischemic tissue necrosis, vascular invasion and thrombosis are easily identified as true mycotic infections [37].

Diagnostic criteria have been described to determine the true pathogenic nature of the organism diagnosed in cytology specimens. The subtle pointers towards a fungus being pathogenic and not contaminant are hemop- tysis or alveolar hemorrhage clinically, concurrent isolation of the pathogen in other sterile body fluid and tissue infiltration in pulmonary biopsy tests [38]. We had tissue diagnosis in 3 cases of Cryptococcus and in 1 case of Aspergillus in the category of mycoses. Histoplasma was identified in pleural effusion and therefore considered as true infection. Detection of Pneumocystis in cytology fluids is considered the true pathogenic nature of the organism.

The question of colonization versus infection is of critical importance necessitating rigorous collection standards especially when treating patients who have presumed nosocomial infections. There are few fungal organisms known to colonize the tracheobronchial tree or upper airway. Aspergillus and Candida species are the most prominent organisms. The issue of colonization versus infection can be solved by thorough clinical history which includes the immune status of the patient, relevant radiological investigations and bronchoscopy findings. A tissue diagnosis should be asked for if clinical suspicion of malignancy is strong and cytology is negative.

\section{Conclusion}

Aspergillus and Candida species are the most common fungal organisms which colonize malignant growths. Invasive candidiasis and aspergillosis may present as a mass lesion and may masquerade malignancy clinically and radiologically. The underlying immune status of the patient may be a clue for differentiating invasive mycoses from colonization. The possibility of the former is significantly higher in immunocompromised hosts as compared to immunocompetent individuals. Hence, in the absence of an immunocompromised status, fungi detection in respiratory tract cytological samples is likely to be colonization and may hide an underlying tumor. Further, the presence of fungal hyphae in exfoliative cytology specimens does not warrant antifungal therapy but a thorough work-up is indicated to rule out true fungal infections.

\section{Disclosure Statement}

None. 


\section{References}

$\checkmark 1$ Ascioglu S, Rex JH, de Pauw B, Bennett JE, Bille J, Crokaert F, Denning DW, Donnelly JP, Edwards JE, Erjavec Z, Fiere D, Lortholary O, Maertens J, Meis JF, Patterson TF, Ritter J, Selleslag D, Shah PM, Stevens DA, Walsh TJ; Invasive Fungal Infections Cooperative Group of the European Organization for Research and Treatment of Cancer; Mycoses Study Group of the National Institute of Allergy and Infectious Diseases: Defining opportunistic invasive fungal infections in immunocompromised patients with cancer and hematopoietic stem cell transplants: an international consensus. Clin Infect Dis 2002;34: 7-14.

-2 Shahid M, Malik A, Bhargava R: Bronchogenic carcinoma and secondary aspergillosis common yet unexplored: evaluation of the role of bronchoalveolar lavage-polymerase chain reaction and some nonvalidated serologic methods to establish early diagnosis. Cancer 2008;113:547-558.

3 Luo BL, Zhang LM, Hu CP, Xiong Z: Clinical analysis of 68 patients with pulmonary mycosis in China. Multidiscip Respir Med 2011;6: 278-283.

4 Smahi M, Serraj M, Ouadnouni Y, Chbani L, Znati K, Amarti A: Aspergilloma in combination with adenocarcinoma of the lung. World J Surg Oncol 2011;9:27.

5 Schwarz J: The diagnosis of deep mycoses by morphologic methods. Hum Pathol 1982;13: 519-533.

-6 Levy H, Horak DA, Tegtmeier BR, Yokota SB, Forman SJ: The value of bronchoalveolar lavage and bronchial washings in the diagnosis of invasive pulmonary aspergillosis. Respir Med 1992;86:243-248.

7 Knox KS, Meinke L: Role of bronchoalveolar lavage diagnostics in fungal infections. Clin Chest Med 2009;30:355-365.

$\checkmark 8$ Huang L, Morris A, Limper AH, Beck JM ATS Pneumocystis Workshop Participants: An Official ATS Workshop Summary: recent advances and future directions in pneumocystis pneumonia (PCP). Proc Am Thorac Soc 2006;3:655-664.

9 Hope WW, Walsh TJ, Denning DW: Laboratory diagnosis of invasive aspergillosis. Lancet Infect Dis 2005;5:609-622.

10 Musher B, Fredricks D, Leisenring W, Balajee SA, Smith C, Marr KA: Aspergillus galactomannan enzyme immunoassay and quantitative PCR for diagnosis of invasive aspergillosis with bronchoalveolar lavage fluid. J Clin Microbiol 2004;42:5517-5522.

11 Hayden RT, Isotalo PA, Parrett T, Wolk DM, Qian X, Roberts GD, Lloyd RV: In situ hybridization for the differentiation of Aspergillus, Fusarium, and Pseudallescheria species in tissue section. Diagn Mol Pathol 2003;12:2126.
12 Franquet T, Müller NL, Giménez A, Guembe $\mathrm{P}$, de La Torre J, Bagué S: Spectrum of pulmonary aspergillosis: histologic, clinical, and radiologic findings. Radiographics 2001;21: 825-837.

13 Babbin BA, Greene JN, Vega R, Iravani S, Ku NN, Sandin RL: Pathologic manifestations of invasive pulmonary aspergillosis in cancer patients: the many faces of aspergillus. Cancer Control 2000;7:566-571.

14 Nilsson JR, Restrepo CS, Jagirdar J: Two cases of endobronchial carcinoid masked by superimposed aspergillosis: a review of the literature of primary lung cancers associated with Aspergillus. Ann Diagn Pathol 2013;17:131-136.

15 Olobatoke AO, David D, Hafeez W, Van T, Saleh HA: Pulmonary carcinosarcoma initially presenting as invasive aspergillosis: a case report of previously unreported combination. Diagn Pathol 2010;5:11.

16 Greaves TS, Strigle SM: The recognition of Pneumocystis carinii in routine Papanicolaou-stained smears. Acta Cytol 1985;29:714720.

17 Paradis IL, Ross C, Dekker A, Dauber J: A comparison of modified methenamine silver and toluidine blue stains for the detection of Pneumocystis carinii in bronchoalveolar lavage specimens from immunosuppressed patients. Acta Cytol 1990;34:511-516.

18 Johnston WW, Schlein B, Amatulli J: Cytopathologic diagnosis of fungus infections. 1. A method for the preparation of simulated cytopathologic material for the teaching of fungus morphology in cytology specimens. 2. The presence of fungus in clinical material. Acta Cytol 1969;13:488-495.

19 Whitaker D, Sterrett GF: Cryptococcus neoformans diagnosed by fine needle aspiration cytology of the lung. Acta Cytol 1976;20:105107.

20 Powers CN: Diagnosis of infectious diseases: a cytopathologist's perspective. Clin Microbiol Rev 1998;11:341-365.

21 Austin P, Dekker A, Kennerdall JS: Orbital aspergillosis: report of a case diagnosed by fine needle aspiration. Acta Cytol 1983;27:166169.

22 Ashton PR: Infectious organisms in cytologic material. Lab Med 1983;14:227-233.

23 Neumann MP, Eng MH, Rholl KE, Swedo GJ, Meranze SG: Disseminated histoplasmosis diagnosed by percutaneous needle biopsy of a retroperitoneal lymph node. A case report. Acta Cytol 1992;36:527-528.

24 Itano H, Andou A, Date H, Shimizu N: Nonsmall cell lung cancer coexisting with pulmonary aspergilloma. Jpn J Thorac Cardiovasc Surg 2005;53:513-516.

25 Shimizu J, Watanabe Y, Oda M, Watanabe S, Hayashi Y, Iwa T, Kamimura R, Takashima T, Nonomura A: A case of lung cancer suspected to be pulmonary mycosis of the fungus ball type. Nihon Kyobu Shikkan Gakkai Zasshi 1990;28:1252-1256.
26 Sangoi AR, Rogers WM, Longacre TA, Montoya JG, Baron EJ, Banaei N: Challenges and pitfalls of morphologic identification of fungal infections in histologic and cytologic specimens: a ten-year retrospective review at a single institution. Am J Clin Pathol 2009;131: 364-375.

27 Crapanzano JP, Zakowski MF: Diagnostic dilemmas in pulmonary cytology. Cancer 2001; 93:364-375.

28 Limper AH: The changing spectrum of fungal infections in pulmonary and critical care practice: clinical approach to diagnosis. Proc Am Thorac Soc 2010;7:163-168.

29 Greene RE, Schlamm HT, Oestmann JW, Stark P, Durand C, Lortholary O, Wingard JR, Herbrecht R, Ribaud P, Patterson TF, Troke PF, Denning DW, Bennett JE, de Pauw BE, Rubin RH: Imaging findings in acute invasive pulmonary aspergillosis: clinical significance of the halo sign. Clin Infect Dis 2007;44:373379.

30 Jain D, Kumar Y, Vasishta RK, Rajesh L, Pattari SK, Chakrabarti A: Zygomycotic necrotizing fasciitis in immunocompetent patients: a series of 18 cases. Mod Pathol 2006;19: 1221-1226.

31 Lui G, Lee N, Ip M, Choi KW, Tso YK, Lam E, Chau S, Lai R, Cockram CS: Cryptococcosis in apparently immunocompetent patients. QJM 2006;99:143-151.

32 Chabé M, Dei-Cas E, Creusy C, Fleurisse L, Respaldiza N, Camus D, Durand-Joly I: Immunocompetent hosts as a reservoir of pneumocystis organisms: histological and rt-PCR data demonstrate active replication. Eur J Clin Microbiol Infect Dis 2004;23:89-97.

33 Rozenbaum R, Gonçalves AJ: Clinical epidemiological study of 171 cases of cryptococcosis. Clin Infect Dis 1994;18:369-380.

34 Feigin DS: Pulmonary cryptococcosis: radiologic-pathologic correlates of its three forms. AJR Am J Roentgenol 1983;141:1262-1272.

- 35 Robinson TD, Barnes DJ, Watson GF: Coexistent cryptococcosis and carcinoma within a solitary pulmonary nodule. Aust NZ J Med 1999;29:561-562.

-36 Kawasaki H, Ishikawa K, Kuniyoshi M, Ohta M, Kawabata T, Hirayasu T: Lung adenocarcinoma with coexisting pulmonary cryptococcoma. Jpn J Thorac Cardiovasc Surg 2004; 52:21-25.

37 Hayden RT, Qian X, Roberts GD, Lloyd RV: In situ hybridization for the identification of yeastlike organisms in tissue section. Diagn Mol Pathol 2001;10:15-23.

38 Vélez L, Correa LT, Maya MA, Mejía P, Ortega J, Bedoya V, Ortega H: Diagnostic accuracy of bronchoalveolar lavage samples in immunosuppressed patients with suspected pneumonia: analysis of a protocol. Respir Med 2007;101:2160-2167. 